\title{
Long-lasting cerebral functional changes following moderate dose x-radiation treatment to the scalp in childhood: an electroencephalographic power spectral study*
}

\author{
ISRAEL YAAR, ELAINE RON, BARUCH MODAN, YOSEFF RINOTT, \\ MINA YAAR, MICHAELLA MODAN \\ From the Hadassah University Hospital, Jerusalem, Israel and the Medical Neurology Branch, \\ National Institutes of Health, Bethesda, MD, USA
}

SUMMARY EEG tracings were compared in 44 young adults who received scalp x-radiation treatment for tinea capitis during childhood and 59 non-irradiated control subjects. The irradiated subjects were exposed, over 20 years previously, to a mean dose of 130 rads to the brain. Visual analysis of the EEG revealed an insignificant excess of abnormalities among the irradiated subjects compared to the controls. Power spectral density function analysis showed increased power values among the irradiated subjects, particularly in the beta wave frequencies. This finding provides further evidence for suspecting that $\mathrm{x}$-irradiation during brain maturation may cause long-lasting damage to the brain tissue.

The immature CNS has been shown to be very sensitive to $\mathrm{x}$-radiation. ${ }^{1-10}$ Electroencephalograms (EEG) of children have responded immediately to $\mathrm{x}$-radiation doses as low as 130 rads, ${ }^{6}$ but long-term EEG follow ups have not yet been done in normal humans and quantitative EEG techniques have been used rarely. ${ }^{3}$

From 1910 to 1960 approximately 200000 children worldwide, and about 20000 children in Israel, received scalp $\mathrm{x}$-ray epilation as treatment for

Address for reprint requests: Dr Israel Yaar, NIH, NINCDS, Building 10, Room 10D18, Bethesda, Md 20205, USA.

Received 26 May 1981 and in revised form 6 September 1981 Accepted 26 September 1981

*Supported by a research agreement no. 06-0-09-3 from the Bureau of Radiological Health, U.S. Public Health Service.

Dr Yaar, Hadassah Hospital, Jerusalem and Medical Neurology Branch, National Institutes of Health, Bethesda, Maryland; Dr Ron, Department of Clinical Epidemiology, Chaim Sheba Medical Center, Tel Hashomer; Dr Modan, Department of Clinical Epidemiology, Chaim Sheba Medical Center; Dr Rinott, Department of Statistics, Hebrew University, Jerusalem; Dr M Yaar, Department of Dermatology, Hadassah Hospital, Jerusalem; Dr M Modan, Department of Clinical Epidemiology, Chaim Sheba Medical Center, Tel Hashomer. tinea capitis. ${ }^{11}$ Dosimetric studies demonstrated that the average radiation dose to the brain was $130^{12}$ or $140^{13}$ rads. An excess risk of head and neck neoplasia, ${ }^{14-19}$ and an elevated risk of mental disorders and admission to psychiatric hospitals have been reported among tinea irradiated populations. ${ }^{20} 21$ In addition, several measures of scholastic aptitude and achievement indicated a tendency for the irradiated subjects to be less successful than the comparison groups. ${ }^{21}$ In this study, quantitative EEG examinations were undertaken to determine whether there are measurable signs of organic cerebral damage.

\section{Materials and methods}

The x-ray therapy followed the Adamson-Kienboch technique and has been reported in detail elsewhere. ${ }^{121322}$ Radiation doses measured on a phantom revealed hemispheric cortical absorption of $121-139$ rads; $2.5 \mathrm{~cm}$ deeper into the hemispheres the absorbed doses were between 95 and 121 rads. ${ }^{12}$ Approximately $10 \%$ of the children were recalled for a second course of treatment due to relapse.

The EEG study subjects were chosen from a previously identified study population of 10842 Israelis irradiated for tinea capitis; 10842 tinea-free, non-irradiated 
population controls and 5400 tinea-free, non-irradiated sibling controls. The control subjects were individually matched to the irradiated subjects on age, country of origin and year of immigration to Israel. ${ }^{18} 19$ The EEG examinees constituted a stratified random sample of members of the original study cohort.

EEG recordings were obtained on 103 subjects, all between the ages of 20 and 35 years: 44 irradiated subjects (IS), 23 males and 21 females, and 59 control subjects (CS), 30 males and 29 females. The mean ages of the four groups IS/CS//males/females were $28 \cdot 6 ; 29 \cdot 1$; 28.7 and 29.4 years respectively. There was no difference in age distribution among the four subgroups. EEGs were obtained by regular paper tracings for clinical visual interpretation and F8-T4; F7-T3; T6-02; T5-01 derivations were tape recorded for Power Spectral Density Function (PSDF) analysis. These EEG tracings were band pass filtered from $2-40 \mathrm{~Hz}, 3 \mathrm{db}$ points, with attenuation of $24 \mathrm{db} /$ octave and analog to digital converted at 128 samples per second. Digitised data (256 data points at a time) were windowed $^{23}$ and Ultra-Fast-FourierTransformed. ${ }^{24}$ The resulting coefficients were squared, summed and averaged repeatedly 60 times, over a total period of two minutes. This produced four PSDFs for each subject, one for each of the four EEG tracings, calculated for $0-30 \mathrm{~Hz}$ at multiples of $0.5 \mathrm{H}_{2}$. The four PSDFs were then averaged together into one representative PSDF with 61 nominal frequency bands (APSDF).

Visual analysis of the paper-recorded EEG tracings was "blindly" performed by one of the investigators (IY). Eight channels were analysed at rest as well as during hyperventilation and photic stimulation. The clinical records were scored as normal or abnormal.

The 60 APSDF $(0 \mathrm{~Hz}$ was not included) values were compared between the IS and CS in a multivariate analysis of variance (SPSS MANOVA), taking into account radiation exposure, sex and their interaction and by repeated $t$ tests. $^{25}$ Two-group discriminant analyses, performed separately for males and females, were also undertaken. ${ }^{25} 26 \mathrm{~A}$ search for subjects with extreme spectral values was performed by four-group discriminant analysis, ${ }^{25}$ but none were found.

\section{Results}

Visual analysis of the EEG records for background activities revealed an insignificant increase in the frequency of abnormalities among the irradiated subjects $(31 \%)$ compared to the control group $(25 \%)$. The overall relative risk (RR) for abnormalities was $1 \cdot 3$ (table 1) and was consistent for males and females $(\mathrm{RR}=1.4$ and 1.2 respectively).

Increased power values among the IS as compared to the CS were observed in 50 out of the $60(83 \%)$ APSDF variables (table 2); differences were found in 23 of the nominal frequency bands, all of them in the beta frequencies. Further analyses, taking sex into account, demonstrated an identical pattern (repeated ANOVA). Higher power values were found for both male and female IS compared to CS and this difference was again most evident in the beta frequency bands.

Looking at all of APSDF variables together (MANOVA), indicated that there was an overall radiation effect $(F=1.90 ; p=0.017)$. Females had higher values than males $(F=2.034 ; p=0.01)$, but sex and radiation interaction was not significant $(F=1 \cdot 36 ; p=0 \cdot 15)$.

Finally, two-group discriminant analyses showed the effect of irradiation to be highly significant for both sexes (males: $F=11.5 ; p=0.0000$; females: $\mathrm{F}=8 \cdot 8 ; \mathrm{p}=0.0001)$.

\section{Discussion}

Our results indicate an increase in EEG power values, in the irradiated subjects compared to controls. The difference in power was particularly evident in the beta frequency band and was found for both males and females. This finding is consistent with the hypothesis that structural changes due to irradiation can lead to an excess of fast or sharp activities in the EEG. ${ }^{27} 28$ The average age of the irradiated children at time of treatment was 7 years. In these years the CNS is still immature and in a state of rapid development ${ }^{29}$ and can be harmed by $\mathrm{x}$-radiation doses as low as 50 rads or less. ${ }^{12530-34}$ Studies performed on young animals demonstrated effects of low dose $\mathrm{x}$-radiation to the brain, ${ }^{12313435}$ although there are

Table 1 Visual evaluation of EEG tracings by exposure category and sex

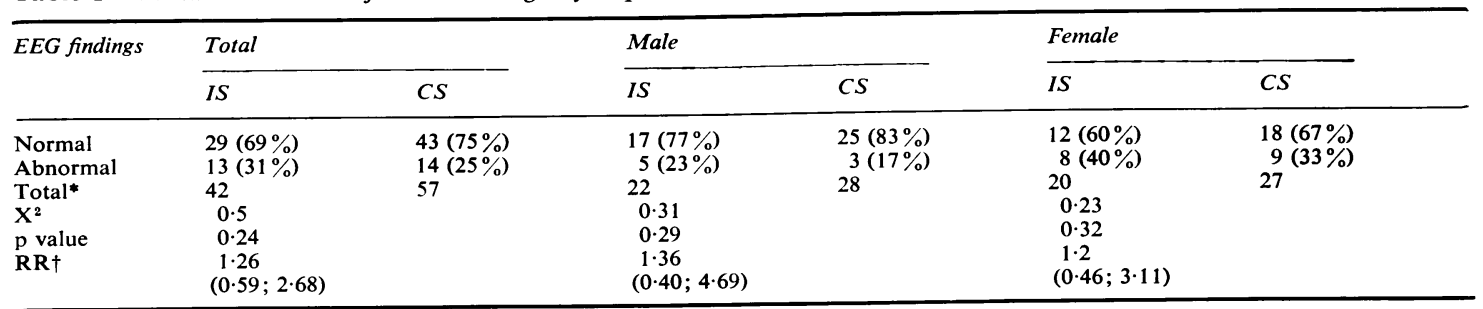

* Paper tracings for 4 persons were not available for clinical evaluation.

+Relative Risk with $95 \%$ Confidence Interval. 
Table 2 Power spectral density function analysis of EEG recordings

\begin{tabular}{|c|c|c|c|c|c|c|c|c|}
\hline \multirow[t]{2}{*}{$H_{2}$} & \multicolumn{2}{|c|}{ Mean power ${ }^{1}$} & \multirow[t]{2}{*}{$H_{2}$} & \multicolumn{2}{|c|}{ Mean power } & \multirow[t]{2}{*}{$\mathrm{H}_{2}$} & \multicolumn{2}{|c|}{ Mean power } \\
\hline & IS & $C S$ & & IS & $C S$ & & IS & $C S$ \\
\hline \multicolumn{3}{|c|}{ Delta frequency } & $10 \cdot 0$ & 331 & 417 & $20 \cdot 0$ & 22 & 19 \\
\hline $0 \cdot 5$ & 3 & 2 & $10 \cdot 5$ & 363 & 327 & $20 \cdot 5$ & 21 & 17 \\
\hline 1.0 & 8 & 7 & $11 \cdot 0$ & 276 & 230 & $21 \cdot 0$ & 21 & $16^{*}$ \\
\hline $1 \cdot 5$ & 41 & 34 & $11 \cdot 5$ & 159 & 160 & $21 \cdot 5$ & 19 & $14^{*}$ \\
\hline 2.0 & 122 & 108 & $12 \cdot 0$ & 112 & 99 & $22 \cdot 0$ & 17 & $13+$ \\
\hline $2 \cdot 5$ & 169 & 152 & $12 \cdot 5$ & 81 & 67 & & & \\
\hline $3 \cdot 0$ & 165 & 143 & 13.0 & 61 & 48 & $22 \cdot 5$ & 15 & $12^{*}$ \\
\hline $3 \cdot 5$ & 143 & 127 & \multicolumn{3}{|c|}{ Beta 1 frequency } & $23 \cdot 0$ & 14 & $11+$ \\
\hline \multicolumn{3}{|c|}{ Theta frequency } & $13 \cdot 5$ & 46 & $38^{*}$ & $23 \cdot 5$ & 12 & $10 \dagger$ \\
\hline $4 \cdot 0$ & 132 & 109 & 14.0 & 41 & $31^{*}$ & $24 \cdot 0$ & 12 & $9 \dagger$ \\
\hline $4 \cdot 5$ & 108 & 97 & $14 \cdot 5$ & 37 & $28^{*}$ & $24 \cdot 5$ & 11 & $8 \dagger$ \\
\hline $5 \cdot 0$ & 92 & 87 & $15 \cdot 0$ & 34 & 27 & $25 \cdot 0$ & 11 & $8 \dagger$ \\
\hline $5 \cdot 5$ & 88 & 83 & $15 \cdot 5$ & 31 & 26 & $25 \cdot 5$ & 10 & $7 \dagger$ \\
\hline 6.0 & 84 & 85 & $16 \cdot 0$ & 30 & 26 & $26 \cdot 0$ & 9 & $7 \dagger$ \\
\hline $6 \cdot 5$ & 91 & 87 & $16 \cdot 5$ & 29 & 24 & $26 \cdot 5$ & 9 & $7 \dagger$ \\
\hline $7 \cdot 0$ & 98 & 97 & $17 \cdot 0$ & 26 & 23 & $27 \cdot 0$ & 8 & $6^{*}$ \\
\hline $7 \cdot 5$ & 117 & 122 & $17 \cdot 5$ & 26 & $22^{*}$ & $27 \cdot 5$ & 8 & $6^{*}$ \\
\hline \multicolumn{3}{|c|}{ Alpha frequency } & 18.0 & 24 & 21 & $28 \cdot 0$ & 8 & $6^{*}$ \\
\hline $8 \cdot 0$ & 139 & 143 & \multicolumn{3}{|c|}{ Beta 2 frequency } & $28 \cdot 5$ & 7 & $6^{*}$ \\
\hline $8 \cdot 5$ & 167 & 187 & $18 \cdot 5$ & 24 & 20 & $29 \cdot 0$ & 7 & $5^{*}$ \\
\hline $9 \cdot 0$ & 186 & 202 & $19 \cdot 0$ & 23 & 20 & $29 \cdot 5$ & 7 & $5^{*}$ \\
\hline $9 \cdot 5$ & 240 & 311 & $19 \cdot 5$ & 22 & 20 & $30 \cdot 0$ & 7 & $5^{*}$ \\
\hline
\end{tabular}

${ }^{1}$ EEG power in arbitrary $\mathrm{V}^{2}$ units (rounded values in thousands).

$* t$ test is significant at $\mathrm{p}<0.05$.

$t t$ test is significant at $\mathrm{p}<0.01$.

conflicting reportings with regard to EEG changes in those studies; some report abundance of fast activities whereas others report slow wave excess. The changes reported in these studies were usually temporary. ${ }^{2} 35$

In humans almost all reports of radiation effects on the EEG are based on patients who received high doses of therapeutic radiation. ${ }^{36-41}$ The tinea capitis populations are unique because they provide an opportunity to study the delayed radiation effects on the normal developing human brain. In a short term clinical EEG investigation ${ }^{6}$ of tinea capitis children, only temporary abnormalities were found, while in another study no EEG changes were observed at all.42 Our study suggests permanent change in human EEG activity following average doses of 130 rads of childhood $x$-irradiation to the brain. The clinical implications of increased beta activity are controversial. 34-45 Among the tinea capitis irradiated subjects elevated risks of brain neoplasia, psychiatric disorders and symptoms have been reported. In addition, several measures of scholastic aptitude and achievement demonstrated a trend for the treated subjects to be less successful. ${ }^{20} 21$ Finally, differences in the visual evoked responses of the irradiated subjects compared to the control group suggest involvement of the reticular activating system. ${ }^{10}$ The precise meaning of the EEG changes found and the extent to which they are related to other brain disorders manifested in this population needs to be clarified. However, these findings are consistent with the general pattern of an association between moderate doses of $\mathrm{x}$-radiation to the brain and a wide spectrum of brain pathology.

\section{References}

${ }^{1}$ Berdjis CC (ed). Pathology of Irradiation. Baltimore: Williams \& Wilkins, 1971.

${ }^{2}$ Furchtgott E (ed). Pharmacological and Biophysical Agents and Behavior. New York: Academic, 1971.

${ }^{3}$ Kobayashi S, Eidelberg E. Spectrum analysis of residual EEG changes following post-natal x-irradiation in rats. Electroencephalogr Clin Neurophysiol 1967;23: 463-7.

${ }^{4}$ Minamisawa T, Sugiyama H, Tsuchiya $\mathrm{T}$ et al. Effects of pre-natal $\mathrm{x}$-irradiation on the visual evoked potential in adult rabbits. $J$ Radiat Res (Tokyo) 1970; $11: 151-6$.

${ }^{5}$ Schade SP, Caveness WF. Alteration in dendritic organization. Brain Res 1968;7:59-86.

${ }^{6}$ Born W, Heirich H. Elektrenzephalographische Veranderungen nach Rontgenepilation des Kopfhaares bei Kindern. Strahlentherapie 1961 ;115:465-77.

${ }^{7}$ Kramer MW, Michaelson SM. Late pathophysiologic changes in head irradiated dogs, review and clinical correlations. Radiat Res 1972;49:563-88.

${ }^{8}$ Ross JAT, Leavitt SR, Holst EA et al. Neurological and electroencephalographic effects of the $\mathrm{x}$ irradiation of the head in monkeys. Arch Neurol Psychiatry 1964;71:238-49.

${ }^{9}$ Sams CF, Aird RB, Adams GD et al. Electrophysiological changes of the central nervous system in response to low-level radiation. In: Haley $\mathrm{TJ}$, Snider RS, Linde SM, eds. Responses of the Nervous System to Ionizing Radiation (2nd International 
Symposium). Boston: Little, Brown, 1964:243-70.

10 Yaar I, Ron E, Modan M et al. Long-term cerebral effects of small doses of x-irradiation in childhood as manifested in adult visual evoked responses. $A n n$ Neurol 1980;8:261-8.

${ }^{11}$ Cipollaro AC, Kallows A, Rupple JP Jr. Measurement of gonadal radiations during treatment for tinea capitis. New York J Med 1959;59:3033-40.

12 Werner A, Modan B, Davidoff D. Doses to brain, skull and thyroid following $x$-ray therapy for Tinea Capitis. Phys Med Biol 1968;13:247-58.

${ }^{13}$ Schultz RJ, Albert RE. Follow-up study of patients treated by $x$-ray epilation for tinea capitis. III. Dose to organs of the head from x-ray treatment of tinea capitis. Arch Environ Health 1968;17:945-50.

14 Albert RE, Omran AR. Follow-up study of patients treated by $\mathrm{x}$-ray epilation for tinea capitis. I. Population characteristics, post-treatment illnesses and mortality experience. Arch Environ Health 1968; 17:899-918.

${ }^{15}$ Shore RE, Albert RE, Pasternack B. Follow-up study of patients treated by $x$-ray epilation for tinea capitis. Resurvey of post-treatment illness and mortality experience. Arch Environ Health 1976;31 : 21-8.

${ }^{16}$ Munk J, Peyser E, Gruszkiewic. Radiation induced intracranial meningiomas. Clin Radiol 1969;20:90-4.

17 Beller AJ, Feinsod M, Sahar A. The possible relationship between small dose irradiation to the scalp and intracranial meningiomas. Neurochirurgia 1972;4: 235-43.

${ }^{18}$ Modan B, Baidatz D, Mart $\mathrm{H}$ et al. Radiation-induced head and neck tumours. Lancet 1974;1:277-9.

19 Ron E, Modan B. Benign and malignant thyroid neoplasms after childhood irradiation for tinea capitis. JNCI 1980;65:7-11.

${ }^{20}$ Omran AR, Shore RE, Markoff RA et al. Follow-up study of patients treated by x-ray epilation for tinea capitis: Psychiatric and psychometric evaluation. Amer J Publ Health 1978;68:561-7.

${ }^{21}$ Ron E, Modan B. Mental function following scalp irradiation in childhood. Proceedings of the Sixth Intl Cong of Radiation Research. Tokyo 1979.

${ }^{22}$ Adamson HG. A simplified method of x-ray application for the cure of ringworm of the scalp. Kienbock's method. Lancet 1909;1:1378-80.

${ }^{23}$ Bingham C, Godfrey MD, Tukey JW. Modern techniques of power spectrum estimation. IEEE Trans Audio and Electroacoustics AU 1967;35:56-66.

${ }^{24}$ DeBoer E, DeJongh HR. Ultrafast Fourier Transform. UFFT IV. Decus Program Library, No. 15-2. Decuscope, Digital Equipment Computer Society, Maynard, MA. 1970.

${ }^{25} \mathrm{Nie}$ NH, Hall CH, Jenkins JG et al. Statistical Package for the Social Sciences, 2nd ed. New York: McGrawHill, Release i9A, 1975.

${ }^{26}$ Lachin JM, Schachter J. On stepwise discriminant analyses applied to physiologic data. Psychophysiology 1974;11:703-9.
27 Jaffe R, Jacobs L. The beta focus: its nature and significance. Acta Neurol Scan 1972;48:191-203.

${ }^{28}$ Pollen DA, Trachtenberg MC. Neuroglia: Gliosis and focal epilepsy. Science 1970;167:1252-3.

29 Jacobson M. Developmental Neurobiology. New York: Holt, Rinehart and Winston, Inc., 1970.

${ }^{30}$ Brawnson RH, Suter DB, Diller DA. Acute brain damage induced by low dosage $\mathrm{x}$-irradiation. Neurology (Minneap) 1963;13:181-91.

${ }^{31} \mathrm{Gangloff} \mathrm{H}$, Hug $\mathrm{O}$. The effects of ionizing radiation on the nervous system. Adv Biol Med Phys 1965;10:1-90.

32 Gilmore SA, Arrington RW. Effects of x-rays on the maturing nervous system. Neurology (Mineap) 1967; 17:1059-67.

${ }^{33}$ Haley TJ, Snider RA. Response of the nervous system to ionizing radiation. Boston: Little, Brown \& Co., 1962.

${ }^{34}$ Hicks SP, D'Amato CJ. Low dose radiation on the developing brain. Science $1963 ; 141: 903-5$.

${ }^{35}$ Baily OT, Ingraham FD, Bering EA. The late effects of tantalum radiation on the cerebral cortex of monkey. $J$ Neuropath Exp Neurol 1958;17:151-7.

${ }^{36}$ Fassetta G, Carli M, Conte G. EEG changes following cranial irradiation with cobalt associated with intrathecal chemotherapy in leukemic children. Riv Neurol 1973;43:392-400.

37 Garwicz S, Aronson AS, Elmquist D et al. Postirradiation syndrome and EEG findings in children with acute lymphoblastic leukemia. Acta Paediatri Scand 1975;64:399-403.

${ }^{38}$ Hakansson CH, Lindgren M, Sulg IA. EEG effects of post-operative irradiation treatment of brain tumor. Act Radiol [Ther] (Stockh) 1969;8:301-10.

${ }^{39}$ Martins AN, Johnston JS, Henry JM et al. Delayed radiation necrosis of the brain. $J$ Neurosurg 1977 ; 43(3):336-45

40 Minamisawa T, Tsuchiya T, Eto $\mathrm{H}$ et al. Changes in the averaged evoked potentials (AEP) of the patients with brain tumors during therapeutic x-irradiation. Nippon Acta Radiologica 1971;30:141-9.

41 Obetz SW, Smithson WA, Grover RV et al. Neuropsychological follow-up study of central nervous system (CNS) function in children with acute lymphocytic leukemia. Proc Am Assoc Cancer Res 1979;20:342.

${ }^{42}$ Kachnic M. EEG examination in children after epilation of the scalp. Preliminary Report. Bratisl Lek Listg 1972;44:616-9.

${ }^{43}$ Gibbs FA, Gibbs EL. Medical Electroencephalography. Reading, MA : Addison Wesley Publishing Company, 1966.

${ }^{44}$ Kiloh LG, McComas AF, Osselton JW. Clinical Electroencephalography. 3rd ed. London: Butterworth, 1972.

${ }^{45}$ Kuhlo W. The Beta rhythms. In: Remond A, ed-inchief. Handbook of Electroencephalography and Clinical Neurophysiology. Vol. 6, Part A. Amsterdam: Elsevier Scientific Publishing Company, 1976:29-46. 